\title{
Determinants of Sovereign CDS Spreads: Evidence from Brazil
}

\author{
Elton O. Silva ${ }^{1} \&$ Wanderlei L. Paulo ${ }^{1,2}$ \\ ${ }^{1}$ University of São Paulo-USP, São Paulo, Brazil \\ ${ }^{2}$ Faculty of Campo Limpo Paulista-FACCAMP, São Paulo, Brazil \\ Correspondence: Wanderlei L. Paulo, Faculty of Campo Limpo Paulista, Brazil. Tel: 55-11-4812-9400. E-mail: \\ wldepaulo@gmail.com
}

Received: May 7, 2015

Accepted: May 21, 2015

Online Published: June 25, 2015

doi:10.5539/ibr.v8n7p102

URL: http://dx.doi.org/10.5539/ibr.v8n7p102

\begin{abstract}
Credit derivatives are important financial instruments used to transfer credit risk of loans and other assets. Among them stands out the so-called sovereign credit default swap (CDS), which works as a kind of insurance against sovereign credit risk. The international literature has shown a correlation between sovereign CDS, CDS index and stock index. The present study aims to identify and analyze the determinants factors of the Brazilian sovereign credit default swap spreads (CDSs Brazil), from a multiple linear regression model adjusted for the period May 2009 to May 2014. The results show that the S\&P 500 has a greater effect on the CDSs Brazil, followed by the factors Bovespa index (Brazilian stock market index), iTraxx index, European index CDS, FX volatility and CDS USA. Moreover, the CDSs Brazil has a positive relationship with the stock indexes and a negative relationship with the other variables, results similar to some studies in the literature.
\end{abstract}

Keywords: CDS index, credit derivatives, sovereign CDS

\section{Introduction}

In general, credit derivatives are financial contracts that work as a protection against financial losses related to credit default. The financial instruments called credit default swaps (CDS) are among the most important credit derivatives products. This is a bilateral contract in which the buyer pays a periodic fee or premium in exchange for a contingent payment by the counterparty (the seller) in the case of credit event occurs (a review about the CDS market can be seen in Moorad (2006)). The literature presents a lot of works related to credit default swaps, covering several aspects and approaches of this instrument such as spillovers, correlations and determinants (see for example Bruyckere et al., 2013; Oliveira, Curto, \& Nunes, 2012; Naifar, 2011; Arce, Mayordomo, \& Pena, 2013).

Among the several types of credit default swaps the sovereign CDS is an important instrument that represents the default risk of an underlying country. The studies on the sovereign CDS and their relationships with global, local and risk variables, are relevant inputs for investors who are interested in the sovereign credit derivatives market. Many works in the literature have studied the impact of financial variables (as market index and CDS index) on sovereign CDS. Particularity, Tokat and Murat (2009) analyze the impact of the CDS index of high-yield corporate bonds (called iTraxx Crossover-iTraxx XO), on sovereign CDS of emerging markets (Brazil, Turkey and South Africa). The study shows a significant impact of the iTraxx XO index on the pricing dynamics of the sovereign CDS prices.

A study between European sovereign debt crisis and CDS market is presented in Atrissi and Mezher (2010). They analyze the data from the PIIGS (Portugal, Ireland, Italy, Greece and Spain), France and Germany for the period from November 2009 to April 2010. The results show that these countries CDS are influencing one another, due to high correlations observed between them. In the same sense, Mayer (2013) studies the impact of the European debt crisis on the valuation of sovereign debt in the euro area, for the period from July 2007 to April 2012, where the results show a structural break in the valuation of sovereign debt at the beginning of the European debt crisis.

Winckelmann and Sørensen (2011) study the determinants of sovereign CDS spreads for 11 European countries, for the period from January 2006 to April 2011, where the iTraxx index appears to be the most dominating factor for the CDS spreads. Similar study is presented in Fender, Hayo and Neuenkirch (2012), but the authors focus on emerging market sovereign CDS over the period from April 2002 to December 2011. The results show that CDS 
spreads are more related to regional and global risk than to country-specific risk factors. Finally, Eyssell, Fung, and Zhang (2013) analyze the determinants of China's sovereign CDS spreads using local and global variables. They conclude that China's domestic economic factors are more relevant to explain the CDS spread in the earlier years, while the impact of global factors has become increasingly important in recent years.

Specifically, the literature presents some works involving Latin American sovereign CDS (see for example Carr \& Wu, 2007; Chen, Wang, \& Tu, 2011; Wang, Yang, \& Yang, 2013). Recently Wang and Yao (2014) investigate the determinants of the return and volatility of sovereign CDS from six Latin American countries (Argentina, Brazil, Chile, Colombia, Mexico and Venezuela) before and after the bankruptcy of Lehman Brothers, using daily data from August 2006 to September 2010, showing that sovereign CDS spreads are significantly influenced by some global financial factors (as CBOE VIX index, TED spread, Greece and German CDS spread). The research presented in this paper aims to study the determinants of Brazilian sovereign credit default swap, considering country-specific variables (such as stock market index and currency volatility) and global variables (such as S\&P 500 and iTraxx index). The determinants are analyzed from a multiple linear regression model, adjusted for the period from May 2009 to May 2014.

The remainder of this paper is organized as follows. Section two describes the methodology and data used to analyze the determinants of Brazilian sovereign CDS. Section three presents the results and discussion. Some final remarks are presented in section four.

\section{Methods}

The determinants of the Brazilian sovereign credit default swap spread were identified and analyzed from a multiple linear regression model, using the Brazilian CDS spread daily log return (namely here by BRcds) as a dependent variable. Using local and global explanatory variables, the regression model is as follows:

$$
\begin{aligned}
\text { BRcds }_{t} & =\beta_{0}+\beta_{1} \text { ITRX } d s_{t}+\beta_{2} \text { TREUcds }_{t}+\beta_{3} \text { TREUBcd }_{t}+\beta_{4} \text { USind }_{t}+\beta_{5} \text { VIXvol }_{t} \\
& +\beta_{6} U S c d s_{t}+\beta_{7} \text { BRfx }_{t}+\beta_{8} \text { BRind }_{t}+\beta_{9} D E F_{t}+\beta_{10} \text { TED }_{t}+\beta_{11}{\text { TRE } 10_{t}+\varepsilon_{t}}
\end{aligned}
$$

Where $\beta_{0}, \beta_{1}, \ldots, \beta_{11}$ are the parameters (constants) and $\varepsilon_{\mathrm{t}}$ is the unobservable random disturbance (or error). The explanatory variables considered as the possible determinants are defined as follows: ITRXcds is the iTraxx Europe CDS index daily log return (5YR); TREUcds is the Thomson Reuters EU sovereign CDS index daily log return (5YR); TREUBcds is the Thomson Reuters European Banks CDS index daily log return (5YR); USind is the U.S. S\&P 500 index daily log return; VIXvol is the CBOE volatility index daily log return (CBOE VIX index); UScds is the U.S. sovereign CDS daily log return (5YR); BRfx is the Brazilian real FX volatility daily $\log$ return; BRind is the Brazilian stock market index daily log return; DEF is the default yield spread between Baa and Aaa Moody's seasoned corporate bond yield daily log return; TED is the spread between 3-Month LIBOR based on US dollars and 3-Month Treasury Bill daily log return; and TRE10 is the 10-year US Treasury constant maturity rate daily log return.

The basic assumptions made about de model (1) are: $\varepsilon_{t}$ is normally distributed; no autocorrelation (or serial correlation) between any two $\varepsilon_{\mathrm{i}}$ and $\varepsilon_{\mathrm{j}}$ (with $\mathrm{i} \neq \mathrm{j}$ ); homoscedasticity of $\varepsilon_{\mathrm{j}}, \operatorname{Var}\left(\varepsilon_{\mathrm{i}} \mid \mathrm{X}_{\mathrm{i}}\right)=\sigma^{2}$; and no perfect multicollinearity among the explanatory variables.

It is important to note that an explanatory variable is considered significant to explain the dependent variable (BRcds) if its parameter $\left(\beta_{\mathrm{i}}\right)$ is statistically significantly different from zero. In this case, the set of significant explanatory variables corresponds to the set of determinants of the Brazilian CDS spread.

The sample data used to estimate the model (1) was collected from Thomson Reuters Datastream (for ITRXcds, TREUcds, TREUBcd, USind, VIXvol, UScds, BRfx and BRind) and from Federal Reserve Bank of St. Louis (for DEF, TED spread and TRE10), during the period from May 2009 to May 2014. The basic assumptions and significance of the parameters were evaluated using appropriate statistical tests (computed through the softwares SPSS and STATA).

\section{Results and Discussion}

This section presents the results obtained from the research, where determinants of the Brazilian sovereign CDS spreads were identified from model (1). Basically, the study was conducted in three steps: verification of the regression model assumptions, identification and analysis of the determinants.

Considering all explanatory variables (ITRXcds, TREUcds, TREUBcds, USind, VIXvol, UScds, BRfx, BRind, DEF, TED and TRE10), the statistical tests used to check the assumptions are presented in tables 1, 2, 3 and 4 . In Table 1 are presented the results for the Durbin-Watson test (using SPSS software), from which the 
autocorrelation (or serial correlation) can be detected. As the Durbin-Watson statistic (DW) is close to 2, there is no statistically significant evidence of autocorrelation at the 5 percent level of significance ( $\alpha=5 \%)$.

Table 1. Durbin-Watson statistic ( $\alpha=5 \%)$

\begin{tabular}{cccc}
\hline $\mathrm{R}$ & $\mathrm{R}$ square & Std. error & Durbin-Watson (DW) \\
\hline 0.667 & 0.445 & 0.024 & 2.051 \\
\hline
\end{tabular}

To check the no perfect collinearity assumption (there are no exact linear relationships among the explanatory variables) it was used the so-called variance inflation factor (VIF). As a common rule, if the VIF of a variable exceeds 10 then this variable is said be highly collinear (this will be a problem for estimating the parameters of the regression model). The Table 2 shows the indicators of multicollinearity for the explanatory variables (by SPSS software), which suggests that the multicollinearity is not a troublesome problem.

Table 2. Collinearity statistics

\begin{tabular}{ccc}
\hline Variable & Tolerance & VIF \\
\hline ITRXcds & 0.660 & 1.514 \\
TREUcds & 0.794 & 1.259 \\
TREUBcds & 0.711 & 1.407 \\
USind & 0.243 & 4.109 \\
VIXvol & 0.334 & 2.994 \\
UScds & 0.896 & 1.116 \\
BRfx & 0.838 & 1.193 \\
BRind & 0.541 & 1.849 \\
DEF & 0.969 & 1.032 \\
TED & 0.977 & 1.024 \\
TRE10 & 0.752 & 1.331 \\
\hline
\end{tabular}

The normally distributed assumption was tested using Kolmogorov-Smirnov and Shapiro-Wilk statistics (by SPSS software). As Table 3 shows both tests have p-values practically zero, then the disturbance $\left(\varepsilon_{\mathrm{i}}\right)$ are not normally distributed (at the 5 percent level). However, if the sample size is relatively large (as is the case), under the assumption of homoscedasticity (that will be tested below) the OLS coefficient estimators are asymptotically normally distributed, such that statistical tests ( $t$ and F) are still valid asymptotically (Wooldridge, 2013, pp. 173).

Table 3. Kolmogorov-Smirnov and Shapiro-Wilk statistics

\begin{tabular}{cccccc}
\hline \multicolumn{2}{c}{ Kolmogorov-Smirnov (KS) } & \multicolumn{3}{c}{ Shapiro-Wilk (SW) } \\
\hline Statistic & $\mathrm{df}$ & $\mathrm{p}$ value. & Statistic & $\mathrm{df}$ & $\mathrm{p}$ value. \\
0.056 & 1240 & 0.000 & 0.976 & 1240 & 0.000 \\
\hline
\end{tabular}

Finally, the assumption of homogeneity was tested using the White test, which is done under the null hypothesis that there is no heteroscedasticity. The Table 4 presents the results for the White test (using STATA software), showing that there is evidence of heteroscedasticity at the 5 percent level of significance (with p value practically zero). If there is heteroscedasticity, then the OLS inference (as t tests and F tests) is generally faulty, even with large sample sizes (note that in this case the $\mathrm{t}$ and $\mathrm{F}$ tests are not valid asymptotically). Under heteroscedasticity, an alternative is to use the White's robust standard error procedure (Wooldridge, 2013, p. 279). 
Table 4. White statistic

\begin{tabular}{ccc}
\hline df & White & p-valor \\
\hline 77 & 165.23 & $2.2 \mathrm{e}-08$ \\
\hline
\end{tabular}

Considering White's procedure, Table 5 presents the regression results (obtained from STATA software). In this case the robust $\mathrm{F}$ statistic is 65.57 , with $\mathrm{p}$ value practically zero, such that there is joint significance of the parameters at the $5 \%$ of significance. However, from $t$ statistics the parameters of the explanatory variables TREUcds, VIXvol, UScds, DEF, TED and TRE10 are not significant at the 5 percent level of significance. Then these variables seem to have no effect on the dependent variable BRcds (Brazilian CDS spread).

Table 5. Result of the regression using White's robust standard error procedure.

\begin{tabular}{|c|c|c|c|c|}
\hline Variable & Coefficient $\left(\beta_{\mathrm{i}}\right)$ & Robust std. error & $\mathrm{t}$ statistic & p-value \\
\hline ITRXcds & 0.22199 & 0.02916 & 7.61 & 0.000 \\
\hline TREUcds & 0.03424 & 0.01931 & 1,77 & 0.076 \\
\hline TREUBcds & 0.08422 & 0.03001 & 2.81 & 0.005 \\
\hline USind & -0.75041 & 0.15040 & -4.99 & 0.000 \\
\hline VIXvol & 0.01834 & 0.01800 & 1.02 & 0.308 \\
\hline UScds & 0.03933 & 0.02015 & 1.95 & 0.051 \\
\hline BRfx & 0.09579 & 0.01719 & 5.57 & 0.000 \\
\hline BRind & -0.34514 & 0.07238 & -4.77 & 0.000 \\
\hline DEF & 0.05594 & 0.04304 & 1.30 & 0.194 \\
\hline TED & 0.01142 & 0.01119 & 1.02 & 0.308 \\
\hline TRE10 & -0.03056 & 0.04579 & -0.67 & 0.505 \\
\hline Intercept & 0.00044 & 0.00068 & 0.65 & 0.513 \\
\hline
\end{tabular}

Note. $\mathrm{F}$ statistic $=65.57$ with $\mathrm{p}$ value $=0.000$.

With the purpose of define the determinants from a statistically significant model, the Table 6 presents the regression results obtained from White's procedure (by backward procedure). Note that from $t$ statistics the parameters of the explanatory variables ITRXcds, TREUBcds, USind, UScds, BRfx and BRind are significant to explain the dependent variable (Brazilian CDS spread), at the 5 percent level of significance. Moreover, the robust $\mathrm{F}$ statistic is 111.89 , with $\mathrm{p}$ value practically zero, such that there is joint significance of the parameters. Then, the sample regression line is as follows

$$
\begin{aligned}
\text { BRcds } & =0.0004+0.2400 \cdot \text { ITRXcds }+0.1054 \cdot \text { TREUBcds }-0.8845 \cdot \text { USind }+0.0458 \cdot U S c d s \\
& +0.0979 \cdot \text { BRfx }-0.3424 \cdot \text { BRind }
\end{aligned}
$$

Where the explanatory variables represent the determinant factors of the Brazilian sovereign credit default swap, explaining $44 \% \quad\left(R^{2}=0,441\right)$ of the total variation in Brazilian CDS spread (BRcds).

\begin{tabular}{|c|c|c|c|c|}
\hline Variable & Coefficient $\left(\beta_{\mathrm{i}}\right)$ & Robust std. error & $\mathrm{t}$ statistic & p-value \\
\hline ITRXcds & 0.24006 & 0.02935 & 8.18 & 0.000 \\
\hline TREUBcds & 0.10546 & 0.03043 & 3.34 & 0.001 \\
\hline USind & -0.88459 & 0.11118 & -7.96 & 0.000 \\
\hline UScds & 0.04588 & 0.01944 & 2.36 & 0.018 \\
\hline BRfx & 0.09794 & 0.01700 & 5.76 & 0.000 \\
\hline BRind & -0.34244 & 0.07311 & -4.68 & 0.000 \\
\hline Intercept & 0.00043 & 0.00068 & 0.64 & 0.523 \\
\hline
\end{tabular}

Table 6. Result of the regression using robust standard error (backward procedure)

Note. $\mathrm{F}$ statistic $=111.89$ with $\mathrm{p}$ value $=0.000 ; \mathrm{R}$-squared $=0.441$. 
Note that the S\&P 500 index (USind) has a greater effect on Brazilian CDS spread (suggesting that Brazil's CDS are higher when the US stock market is greater), followed by Brazilian stock market index (BRind), iTraxx Europe CDS index (ITRXcds), Thomson Reuters European Banks CDS index (TREUBcds), Brazilian real FX volatility (BRfx) and U.S. sovereign CDS (UScds), respectively. Moreover, it is possible to see that a positive (negative) variation in Brazilian CDS occurs when the determinants ITRXcds, TREUBcds, UScds and BRfx increases (decreases). On the other hand, one increase (decrease) in the return of the variables USind and BRind will have a reduction (increase) in Brazilian CDS return.

Specifically, it is possible to see that stock market index is a significant determinant of the sovereign CDS spread as shown in some studies presented in the literature (see for instance Oliveira, Curto, \& Nunes, 2012; Eyssell, Fung, \& Zhang, 2013). In the same sense, the Itraxx index also is an important factor to explain sovereign CDS changes, as described in Tokat and Murat (2009) and Winckelmann and Sørensen (2011). On the other hand, the CBOE VIX index, DEF, TED spread and TRE10 have no significant effect on Brazilian CDS spread, which is different from some results presented in Wang and Yao (2014).

\section{Final Remarks}

This paper presents a study about the determinants factors of the Brazilian sovereign credit default swap spreads, from a multiple linear regression model adjusted for the period May 2009 to May 2014. From this study the determinants of the Brazilian CDS spread are the S\&P 500 index (USind), Brazilian stock market index (BRind), iTraxx Europe CDS index (ITRXcds), Thomson Reuters European Banks CDS index (TREUBcds), Brazilian real FX volatility (BRfx) and U.S. sovereign CDS (UScds).

Specifically, the S\&P 500 index has a greater effect on Brazilian CDS spread, followed by BRind, ITRXcds, TREUBcds, BRfx and UScds, respectively. A positive (negative) variation in Brazilian CDS occurs when the determinants ITRXcds, TREUBcds, UScds and BRfx increases (decreases). On the other hand, one increase (decrease) in the return of the variables USind and BRind will have a reduction (increase) in Brazilian CDS return. Moreover, it is possible to see that the CDSs Brazil has a negative relationship with the stock indexes and a positive relationship with the other variables, results similar to the others studies about sovereign CDS spread presented in the literature. The results obtained in this research contribute to the studies related to the Latin America sovereign credit default swaps, being important inputs for investors who are interested in the international sovereign credit derivatives market.

It should be highlighted that the regression model used to identify the determinants of Brazilian CDS has only eleven explanatory variables and is estimated using the data from the post-crisis period. Thus, one suggestion for future research is to increase the number of possible determinants (global and local), considering other periods of analysis (such as pre-crisis and post-crisis) as well as other types of analysis tools (as panel data for example).

\section{References}

Arce, O., Mayordomo, S., \& Pena, J. I. (2013). Credit-risk valuation in the sovereign cds and bonds markets: Evidence from the euro area crisis. Journal of International Money and Finance, 35, 124-145. http://dx.doi.org/10.1016/j.jimonfin.2013.01.006

Atrissi, N., \& Mezher, F. (2010). Sovereign debt crisis and credit default swaps: The case of Greece and other PIIGS. Retrieved from http://www.fgm.usj.edu.lb/files/a32010.pdf

Bruyckere, V. D., Gerhardt, M., Schepens, G., \& Vennet, R. V. (2013). Bank/sovereign risk spillovers in the European debt crisis. Journal of Banking \& Finance, 37, 4793-4809. http://dx.doi.org/10.1016/j.jbankfin.2013.08.012

Carr, P., \& Wu, L. (2007). Theory and evidence on the dynamic interactions between sovereign credit default swaps and currency options. Journal of Banking \& Finance, 31, 2383-2403. http://dx.doi.org/10.1016/j.jbankfin.2006.09.008

Chen, Yi-Hsuan, Wang, K., \& Tu, A. H. (2011). Default correlation at the sovereign level: Evidence from some Latin American markets. Applied Economics, 43, 1399-1411. http://dx.doi.org/10.1080/00036840802600467

Eyssell, T., Hung-Gay, F., \& Zhang, G. (2013). Determinants and price discovery of China sovereign credit default swaps. China Economic Review, 24, 1-15. http://dx.doi.org/10.1016/j.chieco.2012.09.003

Fender, I., Hayo, B., \& Neuenkirch, M. (2012). Daily pricing of emerging market sovereign CDS before and during the global financial crisis. Journal of Banking \& Finance, 36, 2786-2794. http://dx.doi.org/10.1016/j.jbankfin.2012.06.017 
Mayer, M. A. (2013). Structural view of sovereign risk contagion in the Euro zone. Retrieved from http://papers.ssrn.com/sol3/papers.cfm?abstract_id=2000662

Moorad, C. (2006). The credit default swap basis. New York: Bloomberg Press.

Naifar, N. (2011). What explains default risk premium during the financial crisis? Evidence from Japan. Journal of Economics and Business, 63, 412-430. http://dx.doi.org/10.1016/j.jeconbus.2010.09.003

Oliveira, L., Curto, J. D., \& Nunes, J. P. (2012). The determinants of sovereign credit spread changes in the Euro-zone. Journal of International Financial Markets, Institutions and Money, 22, 278-304. http://dx.doi.org/10.1016/j.intfin.2011.09.007

Tokat, E., \& Murat, A. (2009). Credit default swaps: iTraxx Crossover index as an emerging markets' portfolio indicator. Investment Management and Financial Innovations, 6(4), 59-66.

Wang, A. T., \& Yao, C. (2014). Risks of Latin America sovereign debts before and after the financial crisis. Applied Economics, 46(14), 1665-1676. http://dx.doi.org/10.1080/00036846.2014.881976

Wang, A. T., Sheng-Yung, Y., \& Nien-Tzu, Y. (2013). Information transmission between sovereign debt CDS and other financial factors-The case of Latin America. North American Journal of Economics and Finance, 26, 586-601. http://dx.doi.org/10.1016/j.najef.2013.02.023

Winckelmann, D. A., \& Sørensen, L. K. (2011). Analysis of European sovereign CDS spreads before and after the financial crisis. Retrieved from http://pure.au.dk/portal-asb-student/files/39700301/thesis.pdf

Wooldridge, J. M. (2013). Introductory Econometrics: A modern approach. South-Western: Cengage Learning.

\section{Copyrights}

Copyright for this article is retained by the author(s), with first publication rights granted to the journal.

This is an open-access article distributed under the terms and conditions of the Creative Commons Attribution license (http://creativecommons.org/licenses/by/3.0/). 